\title{
Genetic diversity associated with agronomic traits using microsatellite markers in Pakistani rice landraces
}

\author{
Zahida Hassan Pervaiz* \\ Department of Biochemistry \\ Quaid-i-Azam University \\ Islamabad, Pakistan \\ E-mail: zahidahasan82pk@hotmail.com \\ M. Ashiq Rabbani \\ Institute of Agri-Biotechnology and Genetic Resources \\ National Agricultural Research Center \\ Park Road, Islamabad, Pakistan \\ Ishtiaq Khaliq \\ School of Life Sciences \\ University of Sussex, Brighton, UK \\ Stephen R. Pearce \\ School of Life Sciences \\ University of Sussex, Brighton, UK \\ Salman A. Malik \\ Department of Biochemistry \\ Quaid-i-Azam University \\ Islamabad, Pakistan
}

Financial support: Agricultural Linkages Program, PARC under the AREP and Higher Education Commission, Islamabad, Pakistan provided funds in the form of scholarship to first author.

Keywords: genetic diversity, landraces, microsatellite markers, Oryza sativa L., Pakistan, rice.

Genetic diversity underlies the improvement of crops by plant breeding. Land races of rice (Oryza sativa L.) can contain some valuable alleles not common in modern germplasm. The aim here was to measure genetic diversity and its effect on agronomic traits among rice land-race genotypes grown in Pakistan. Diversity was measured using thirty-five microsatellite markers and seventy-five genotypes. Among the markers used a total of 142 alleles were detected at 32 polymorphic SSR loci, while three loci were monomorphic in Pakistani rice landraces. The number of alleles identified by each marker ranged from 2 to 13 with a mean of 4.4. Size differences between the smallest and largest alleles varied from 11bp to 71bp. Polymorphism information content ranged from 0.124 to 0.836 , with an average of 0.569. At nine microsatellite loci, basmati-type landraces amplified more different alleles than those in the coarse-type. DNA markers RM70 and RM72 divided the rice landraces on the basis of days to flowering. A dendrogram based on total microsatellite polymorphism grouped 75 genotypes into four major clusters at 0.40 similarity coefficient, differentiating tall, late maturing and slender aromatic types from the short, early and bold non-aromatic ones. It inferred that Pakistani landraces have diverse genetic bases and can be utilized in future breeding programs. The DNA markers developed will assist in genotype identification, purity testing and plant variety protection.

Landraces are precious genetic resources, because they contain huge genetic variability which can be used to complement and broaden the gene pool of advanced genotypes (Kobayashi et al. 2006). The extent of genetic diversity in a crop population depends on recombination, mutation, selection and random genetic drift. Mutation and recombination bring new variations to a population, whereas selection and genetic drift remove some alleles, often from agronomically important lines. Basmati is one of the premium aromatic rice varieties in the world and cultivated in foothill of Himalayas spread over Pakistan and India. The main characteristic feature of basmati rice is its typical fragrance and 1 to 1.5 -fold elongation of rice during cooking Rice (Oryza sativa L.) is one of the significant cereal commodities (Lopez, 2008). Rice fulfills the nutritional requirements of half of the world's population. Pakistan is among world's countries having an abundance

*Corresponding author 
of basmati landraces. Unfortunately many have been lost during last three decades after green revolution. A number of traditional varieties and improved cultivars have been released for cultivation in different regions of Pakistan since early nineteen century. Aromatic cultivars and advanced breeding lines have a narrow genetic base as they are all related to selected basmati lines. Further, a very limited number of basmati breeding lines were used repeatedly in breeding programs to advance grain quality. Unfortunately resistance against biotic and abiotic stresses were not priorities. In Pakistan, out of seven basmati varieties currently under cultivation, five have 'Basmati370 ' as one of the parents (Rabbani et al. 2008). There is a strong need to not only conserve landrace genotypes but also broaden the gene-pool of aromatic rice for future utilization in breeding of high yielding, superior quality and better-adapted varieties in the country.

Exploring diversity in a landrace collection is very important for identifying new genes and further improvement of the germplasm (Aggarwal et al. 2002; Brondani et al. 2006; Jayamani et al. 2007; and Thomson et al. 2007). In the past many efforts have been made to assess the genetic diversity and relationships among germplasm collections of rice using DNA markers. However, limited genetic analyses of Pakistani rice are available from DNA markers. Microsatellites (also known as simple sequence repeats) are simple; tandemly repeated 5-20 fold; often dito tetra-nucleotide; sequence motifs; each flanked by unique sequences. They are valuable as genetic markers because: they are co-dominant in nature; show high allelic diversity; are easily and economically assayed by PCR; and their use may be automated. Tens of thousands of potential SSRs have been identified in rice, and over 25,000 have been developed as molecular markers (Temnykh et al. 2000; McCouch et al. 2002; IRGSP 2005). These markers are currently being used to develop high density genetic maps, genotype rice accessions, determine the genetic structure, optimize the assembly of core collections, and for marker-assisted breeding (McCouch et al. 2002; Yu et al. 2003; Garris et al. 2005).

In rice, SSR markers have been effectively utilized for many purposes including (i) genome mapping (Temnykh et al. 2000; McCouch et al. 2002); (ii) assessment of the genetic diversity and relatedness among various cultivars including both aromatic and non-aromatic rice (Ravi et al. 2003; Jain et al. 2004; Saini et al. 2004; Siwach et al. 2004; Ghneim Herrera et al. 2008); (iii) identification and purity testing of varieties (Coburn et al. 2002; Nagaraju et al.

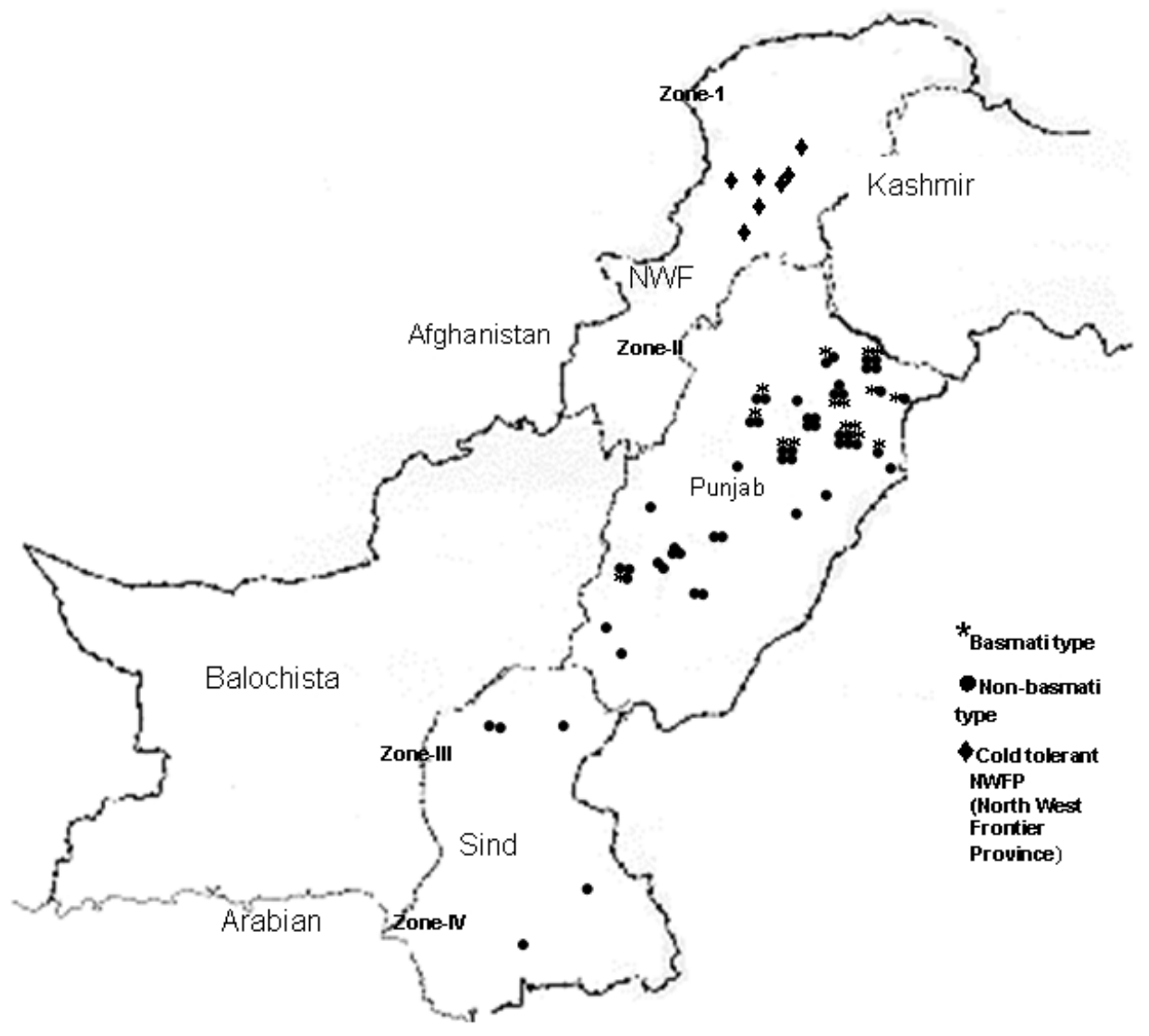

Figure 1. Map showing collection of landraces from four rice growing ecological zones of Pakistan. 
2002; Singh et al. 2004; Joshi and Behera 2006) and (iv) determination of the genetic relationship between several sub-species ( $\mathrm{Ni}$ et al. 2002). In most of these studies, basmati types clustered into a separate group distinct from that of indica and japonica rice varieties (Aggarwal et al. 2002; Nagaraju et al. 2002; Jain et al. 2004). Therefore, basmati germplasm may have a long, independent and complex pattern of evolution that distinguishes it from other groups within Oryza sativa (Jain et al. 2004).

The present study has been conducted to evaluate the pattern and extent of genetic variability and relatedness among some rice landraces of Pakistan based on important agronomic traits using SSR markers. DNA marker analysis will help the identification and differentiation of landraces with different genetic make-up. The information will enable maximized selection of diverse parents and assist in broadening the germplasm base of future rice breeding programs.

\section{MATERIALS AND METHODS}

\section{Plant material}

Seventy two landrace genotypes and three commercial check varieties, Super Basmati (Indica type, aromatic), IR6 (indica type, non-aromatic) and JP5 (Japonica type, nonaromatic) of rice were used in this study. The research material represented the landraces of local rice collected from four ecological zones of Pakistan (Figure 1). A detailed description of the materials used in present investigation is shown in Table 1 and Table 2.

\section{Microsatellite marker analysis}

Total genomic DNA was extracted from 2-3 seed samples from five individuals of each landrace using Kang et al. (1998) with minor modification (mature dry seeds were ground to fine powder rather than whole seed. Purity and concentration of DNA was monitored spectrophotometrically at a wavelength of 260 and $280 \mathrm{~nm}$ using NanoDrop ND-1000 Spectrophotometer (Wilmington, USA). All DNA samples were diluted to a working concentration of $20 \mathrm{ng} / \mu \mathrm{l}$ with TE before use. An equal amount of genomic DNA from 5 individuals of each landrace was mixed to make a bulk sample for microsatellite PCR analysis.

Thirty five primer pairs covering all twelve chromosomes were selected for the genetic diversity analysis on the basis of published rice microsatellite framework map. Three primers (RM5, RM210 and RM229) exhibited monomorphic fragments and were therefore excluded from further analysis. The original source, repeat motifs, primer sequences and chromosomal positions for these markers can be found in the rice genome database (http://www.gramene.org). Microsatellite primer pairs were obtained from Hokkaido Science System (Sapporo, Hokkaido, Japan).
SSR analysis was performed following the protocol of Ravi et al. (2003) with minor modifications. PCR amplification reactions were carried out in a total volume of $20 \mu \mathrm{l}$ containing; $10 \mathrm{mM}$ Tris $\mathrm{HCl}(\mathrm{pH} 8.3$ ); $50 \mathrm{mM} \mathrm{KCl} ; 1.5$ $\mathrm{mM} \mathrm{MgCl} ; 200 \mu \mathrm{M}$ each of deoxynucleotide triphosphate (dNTP); $0.2 \mu \mathrm{M}$ of each forward and reverse primer; 1 unit Taq DNA polymerase (Fermentas Life Sciences); and $20 \mathrm{ng}$ of template DNA. The PCR amplifications were carried out using a MyGene Series Peltier Thermal Cycler (UniEquip $\mathrm{GmbH}$, Munich, Germany). Thermal cycler was programmed to 1 cycle of $5 \mathrm{~min}$ at $94^{\circ} \mathrm{C}$ as an initial hot start and strand separation step. This was followed by 35 cycles of $1 \mathrm{~min}$ at $94^{\circ} \mathrm{C}$ for denaturation, $1 \mathrm{~min}$ for annealing temperature depending on the marker used $\left(55^{\circ} \mathrm{C}-65^{\circ} \mathrm{C}\right)$ and $2 \mathrm{~min}$ at $72^{\circ} \mathrm{C}$ for primer elongation. Finally, 1 cycle of $7 \mathrm{~min}$ at $72^{\circ} \mathrm{C}$ was used for final extension. Amplified products were stored at $-20^{\circ} \mathrm{C}$ until further use. The reproducibility of the amplification products was checked twice for each primer.

\section{Electrophoresis of amplified products}

After amplification, a $15 \mu \mathrm{l}$ aliquot of the amplified SSR samples was combined with $3 \mu \mathrm{l}$ of a loading buffer $(0.4 \%$ $(\mathrm{w} / \mathrm{v})$ bromo-phenol blue, $0.4 \%(\mathrm{w} / \mathrm{v})$ xylene cyanole and 5 $\mathrm{ml}$ of glycerol) and was analyzed directly on $3 \%(\mathrm{w} / \mathrm{v})$ Gene Choice High Resolution agarose (CLP, USA) gels in $1 \times$ TBE buffer (10mM Tris-Borate, $1 \mathrm{mM}$ EDTA) containing $0.5 \mu \mathrm{g}$ per $\mathrm{ml}$ of ethidium bromide. A $25 \mathrm{bp}$ DNA ladder (Biolabs, New England, UK) was used as a size marker to compare the molecular weights of amplified products. After electrophoresis, the gels were documented using an UVI Doc Gel Documentation System (UVITEC, Cambridge, UK).

\section{Allele scoring and data analysis}

Ethidium bromide staining of agarose gels generally showed several bands. The size of the most intensively amplified band for each microsatellite marker was determined based on its electrophoretic mobility relative to molecular weight markers (increments of $25 \mathrm{bp}$ ). Amplified products from SSR analysis were scored qualitatively for presence and absence of each marker allele-genotype combination. Each SSR band amplified by a given primer was treated as a unit character. Data was entered into a binary matrix as discrete variables, 1 for presence and 0 for absence of the character. The most informative primers were selected based on the extent of polymorphism. The polymorphic information content (PIC) value of a marker was calculated according to Anderson et al. (1993). Mean allele numbers, PIC values, and genetic similarities were calculated on the basis of different rice landraces, chromosomes and microsatellite classes. Pair-wise comparisons of the genotypes based on the proportion of unique and shared amplification products (alleles) were used to measure the genetic similarity by Dice coefficients using PAST program (Hammer et al. 2001). Genetic similarities $(\mathrm{F})$ between all pair of the landraces were 
Table 1. Accession number and local name of landraces.

\begin{tabular}{|c|c|c|c|c|c|}
\hline Accession No. & Local name & Accession No. & Local name & Accession No. & Local name \\
\hline 6627 & Bungua-147 & 6549 & Basmati-372 & 6599 & Sufaida-20 \\
\hline 6722 & SathraSufaid-331 & 6516 & SonFine-43 & 6603 & BagarSugdasi-34 \\
\hline 6560 & Basmati-410 & 6530 & $\begin{array}{l}\text { PalampuriBasmati- } \\
137\end{array}$ & 6605 & Sonoattar-45 \\
\hline 6626 & Jhona-145 & 6771 & 15 & 6611 & DaggarSufaid-94 \\
\hline 6558 & KamohBasmati-392 & 6560 & Basmati-410 & 6613 & DhanKasarwala-102-4 \\
\hline Super & Check-1 & 6574 & Begmi-119A & 6622 & Dhan-133 \\
\hline JP5 & Check-2 & 6623 & Begmi-135 & 6597 & RB-3 \\
\hline 6593 & Rohru-414 & 6670 & $\begin{array}{l}\text { MundearaDhan- } \\
90 \mathrm{~S}\end{array}$ & 6745 & Jhona-101 \\
\hline 6620 & Jhona-129 & 6756 & 400 & 6633 & Tiri-219 \\
\hline 6677 & BasmatiSurkh-161 & 6519 & Begmi-51A & 6655 & MunjiSuffaid-23A \\
\hline 6638 & $268-A$ & 6505 & KalaBunda-50 & 6676 & WhiteMunji-160 \\
\hline 6621 & DhanKasarwala-131 & 6507 & Hansraj-54 & 6683 & Jhona-178 \\
\hline 6642 & BamlaSuffaid-320 & 6693 & 213-B & 6684 & 180-CoarseVar \\
\hline 6654 & BaggiMunji-22 & 6564 & Begmi & 6694 & Sufaida-222B \\
\hline 6658 & CoarseWhite-40 & 6527 & Chamber-128 & 6698 & Tiri-236 \\
\hline 6751 & 336-Tiri & 6509 & Hansraj-62 & 6705 & $274-A$ \\
\hline 6664 & MunjiSufaid-165 & IR6 & Check variety & 6706 & Sathri-275 \\
\hline 6663 & 76S-CoarseRice & 6711 & LalDhan-304 & 6717 & Sathra-318 \\
\hline 6779 & $20-A$ & 6758 & Tiri-424-2 & 6719 & Kanhra-8-327 \\
\hline 6520 & Begmi-51S & 6570 & LalDhan-304 & 6724 & DhanDesi-336 \\
\hline 6740 & Baggi-423 & 6578 & Rohdu-150 & 6729 & 349-CoarseWhite \\
\hline 6537 & Basmati-242 & 6582 & EB-204 & 6731 & 353 \\
\hline 6563 & BasmatiKamon & 6588 & Dhan-300 & 6734 & 368 \\
\hline 6766 & 8 & 6590 & Kanhgra-319 & 6755 & 399 \\
\hline 6515 & Basmati-1-1A & 6595 & $\mathrm{~N}-35$ & 6760 & $1-A$ \\
\hline
\end{tabular}

calculated according to Nei and Li (1979). A dendrogram was constructed using pair-group method to get genetic relationships among landraces. The reliability of the dendogram was tested by bootstrap analyses with 10,000 replications to assess branch support. Some workers consider that the confidence limits obtained in bootstrap must be over $95 \%$ in order to consider the grouping of taxa (a group of genetically similar organisms that are classified together as e.g. species, genus, or family) at a branch to be statistically significant (Felsenstein, 1985). Others use a lower limit (above $50 \%$ or at least $50 \%$ ) as indicating statistical support for the topology at a node (Highton, 
1993). In our study we used the lower limits to assess grouping of taxa to be statistically significant because we observed that as the number of test sample increases the confidence interval decreases.

\section{RESULTS}

Thirty-five microsatellite or SSR markers (Table 3) covering all 12 chromosomes were utilized to characterize and assess genetic diversity among seventy-five diverse rice landraces from Pakistan. Only three loci (RM5, RM210 and RM229) were observed monomorphic in Pakistani landrace genotypes. A considerable level of variability was observed among different landraces for remaining thirty two microsatellite loci. In most of the cases, basmati check and other aromatic cultivars exhibited similar banding patterns. The microsatellites exhibited several bands that were shared among the check Super Basmati and some landraces, whereas a few bands were shared among IR6 and other landraces Pakistani rice. Nine accessions $(6626,6756$, $6530,6519,6549,6514,6698,6654$, and 6751) displayed unique bands in comparison with all other genotypes with different microsatellite markers. Interestingly, many loci revealed characteristic alleles in some landraces which were not produced in any of the check varieties used.

Each of the primer pairs differed significantly in their ability to determine variability among the landraces (Table 3 ). Some primers generated several markers, while others generated only few. A total of 145 alleles were detected across 75 rice cultivars/landraces using 32 SSR markers (Table 3). Of these, $142(98 \%)$ were found to be polymorphic. The maximum number of polymorphic alleles (i.e. 13 bands) was obtained with the marker RM70, while the minimum number of polymorphic bands ( 2 alleles) was amplified with the markers RM10, RM13, etc. The average number of polymorphic alleles per marker was 4.4. The overall size of the amplified product varied from $75 \mathrm{bp}$ (RM1) to 349 bp (RM182). The size difference between the smallest and the largest allele at a given SSR locus varied from 12 (RM122) to $71 \mathrm{bp}$ (RM302).

A total of $32(22 \%)$ rare alleles were observed among 12 of the 32 SSR loci, with an average of 2.7 rare alleles per locus. The maximum number of rare alleles were observed at RM163 locus ( 6 alleles), followed by RM70 and RM252 loci (5 alleles each). In general, markers detecting a greater number of alleles per locus detected more rare alleles.

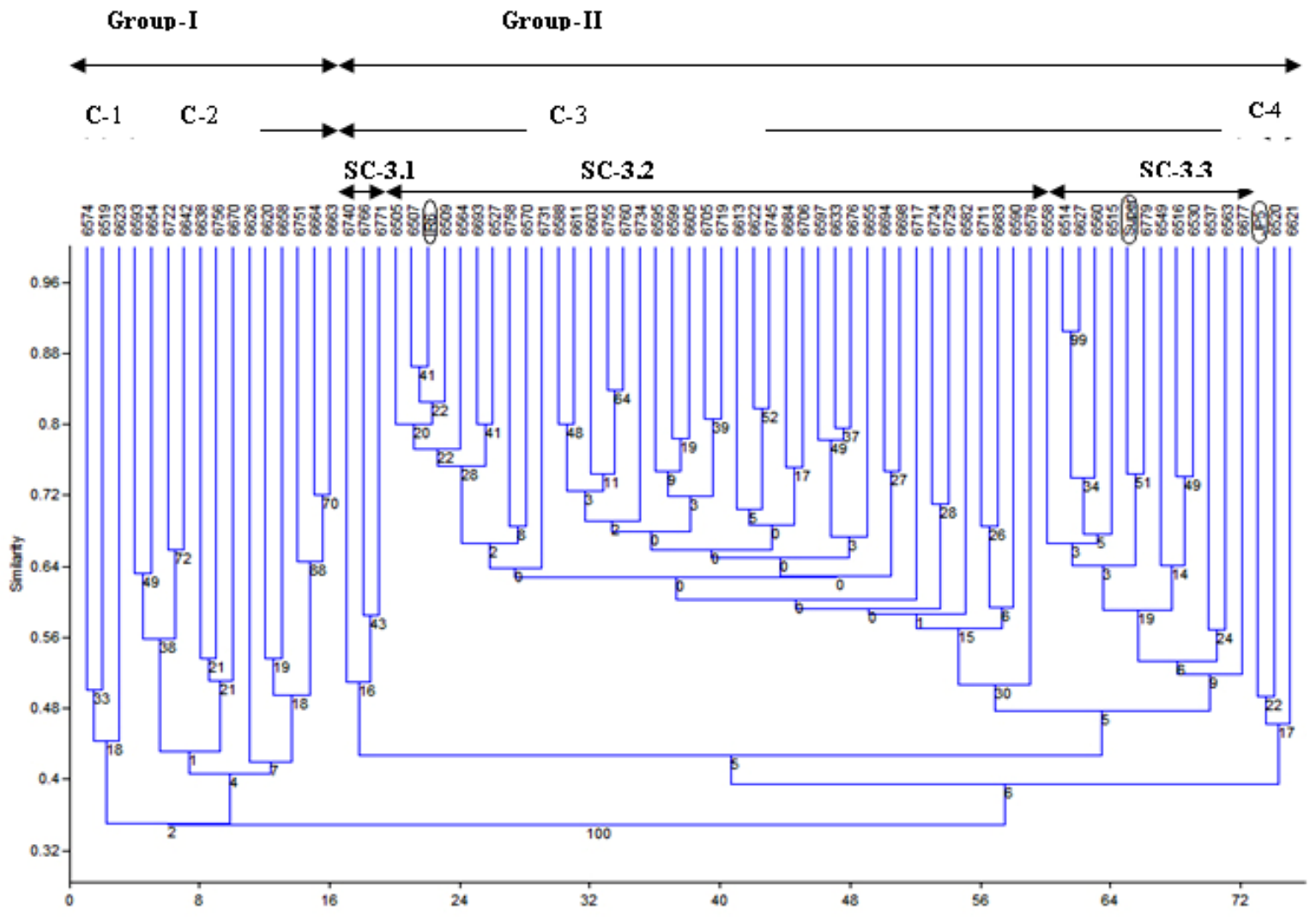

Figure 2. UPGMA cluster analysis showing the diversity and relationship among 75 landraces of rice based on 145 alleles generated by 32 SSR markers. Super-basmati, IR6 and JP5 indicated in circles.Group I (C = Cluster, SC= Sub Cluster)) C1: cluster 1 (cold tolerant, short grained genotypes), C2: cluster 2 (early maturing, tall height, medium seed length, zone II), Group II C3: cluster 3 (Three Sub clusters(SC): SC1: Early maturing Zone III, SC2: Non-Basmati type, SC3: Basmati type) C4: Cluster 4 (Japonica type landraces from northern areas). 
Twenty-one $(60 \%)$ of the rice landraces had rare SSR alleles. The maximum number of rare alleles were present in two landraces, 6626 and 6740 (3 rare alleles each). Two rare alleles were found in each of '6722', '6558, '6621', '6654', '6652', '6530', and '6756', while 12 landraces had single rare allele at individual locus. A landrace was assigned null allele for an SSR locus whenever an amplification product could not be detected for a particular genotype-marker combination. In the set of 75 genotypes, 2 loci showed null alleles. Null alleles were observed in 'Super-basmati' at the RM241 locus and, in '6574'and '6623' at the RM60 locus.

The level of polymorphism among the 75 genotypes was evaluated by calculating PIC values for each of the 32 SSR loci. The PIC values varied widely among loci and ranged from 0.124 (RM10) to 0.836 (RM163) with an average of 0.569 per locus (Table 3 ). PIC values showed a significant positive linear correlation with number of alleles at SSR locus ( $\mathrm{r}=0.73 ; \mathrm{P}<0.01$, analysis of variance). ' 6558 ' and ' 6717 ' gave the maximum numbers of alleles (43). It was followed by ' 6677 ' and ' 6515 ' producing 40 alleles each, while cultivars 'JP5', '6771', '6574' and '6623' gave the least number of alleles (i.e. 34 alleles each) followed by 6626 and 6745 gave 35 alleles each.

A similarity matrix based on the proportion of shared SSR fragments was used to establish the level of relatedness between the various landraces surveyed. Pair-wise estimates of similarity ranged from 0.14 to 0.90 and the average similarity among all 75 landraces was 0.52 (data not shown). Two genotypes 6627 and 6514 were the closest related genotypes with the highest similarity index of $90 \%$. This was followed by $86 \%$ similarity between two pairs of genotypes 6507 and check variety IR-6. The lowest similarity (13\%) was observed between genotypes 6626 and 6745. As expected, genetic similarities between the IR6 and landraces were comparatively high. Among the basmati type landraces, similarity coefficients ranged from 0.22 to 0.90 , whereas non-basmati types showed similarity coefficients of 0.19 to 0.72 . Although comparison of basmati type landraces indicated that these were closely related. Of the landraces analyzed, 6626 had the greatest dissimilarity with all the other tested genotypes. The similarity coefficients of 6626 with all the other landraces ranged from 0.13 to 0.49 .

A UPGMA cluster diagram grouped the 75 Pakistani landraces into two major groups at $100 \%$ confidence interval, effectively differentiating the slender aromatic rice cultivars from the short bold and long bold non-aromatic landraces at similarity coefficient value of 0.34 (Figure 2). Group-I consisted 16 genotypes which are further subdivided into two clusters, cluster-I containing three cold tolerant short grained genotypes, 6574 (Malakand), 6519 (Dir) and 6623 (Swat) while cluster-II consist of 13 landraces (Early maturing, tall heighted and medium seed length) from different regions of Punjab province (Zone-II) except one 6638 from NWFP (Zone-I). Group-II consisted of two major clusters, one grouping two short grained landraces with JP5 a japonica type check variety, while other consisting of total 56 landraces further divided into three sub clusters, one combining IR6, a non-basmati check variety with 39 landraces and 12 basmati type long grained and tall plants together with Super- basmati check variety, third sub cluster grouping non basmati type, two landraces from Zone-III, 6771 (Sangarh) and 6766 (Larhkana) and one from (6740) Sheikhupura. Cluster analysis placed most of the traditional tall, long-grained cultivars together showing a high level of genetic relatedness. However, the clusters formed by the basmati type were distinct from those of the non-aromatic group. Three japonica genotypes were clustered together in group II, and closer to the aromatic cultivars than to the non-aromatic indica group. Dendograms showed that the genotypes that are derivatives of genetically similar types clustered together. Landraces in the same subgroup usually shared a high proportion of ancestry and/or agronomic characteristics such as height, maturity, quality traits, etc. The landraces originating from various regions of Pakistan form well defined, distinct, groups in the cluster analysis, indicating association between the SSR patterns and the geographic origin of genotypes used.

\section{DISCUSSION}

One main cause of eradication of plant genetic resources has been the adaptation of narrowly based advanced varieties for intensive cultivation practices. Variation in landraces is helpful for broadening the crop gene pool (Frankel and Soulé, 1981). Diversity exploration among plant landraces made necessary by the failure of the green revolution to be sustained. Little was known about the relationship between Pakistani agronomic crop cultivars in general and rice landraces in particular on the basis of SSR analysis. Here, 35 microsatellite markers were used to assess the genetic diversity of 75 genotypes of rice including three check varieties Super-basmati (Indica type, aromatic), IR6 (Indica type, Non-aromatic) and JP5 (Japonica type, non-aromatic). Some agronomic features of selected rice landraces e.g. plant height, days to maturity and seed length along with their local names and location are included in the Table 1 and Table 2. The results indicated significant genetic variation among the rice landraces of Pakistan. Microsatellite assays identified a number of alleles that were shared among the Superbasmati and some landraces. A close relationship between 'Super-basmati' and a group of twelve landrace genotypes $(16 \%)$ was observed. That phenomenon could be a favour towards strong discrimination power of some of the DNA markers. However, the similarity coefficient of these landraces ranged from 0.47 to 0.75 compared with Superbasmati rice. These landraces also shared many morphological and agronomic traits with Super-basmati (Indica type) that strengthen the supposition of close relationship between them. 'Check variety 'IR6' (Indica type and non-aromatic) shared limited number of fragments with $54 \%$ of landraces (shown in group II of dendrogram), 
Microsatellite marker based genetic diversity associated with agronomic traits

Table 2. Classification of landraces on the basis of Agronomic traits and geographical location.

\begin{tabular}{|c|c|c|}
\hline $\begin{array}{l}\text { Agronomic traits and } \\
\text { locations }\end{array}$ & Levels & Accessions \\
\hline \multirow[t]{4}{*}{ *Days to Maturity } & Very Early & 6514, JP5, 6638, 6621, 6560, 6756, 6758, 6570, 6655, 6731, 6734, 6755 \\
\hline & Early & $\begin{array}{l}6627,6722,6626,6593,6620,6642,6654,6658,6751,6664,6663,6779,6740 \\
6766,6771,6574,6623,6670,6693,6711,6578,6582,6586,6590,6595,6599 \\
6603,6605,6611,6613,6622,6597,6745,6633,6676,6684,6694,6698 \\
6717,6729\end{array}$ \\
\hline & Medium & $6719,6724,6705,6760,6507,6564,6509$, IR6 \\
\hline & Late & $\begin{array}{l}\text { 6558, Super- Basmati, } 6677,6520,6537,6563,6515,6549,6516,6530,6519 \text {, } \\
6505,6527,6683,6706\end{array}$ \\
\hline \multirow[t]{3}{*}{ *Plant Height } & Tall & $\begin{array}{l}6627,6722,6593,6620,6642,6654,6658,6751,6664,6663,6779,6740,6766, \\
6771,6574,6623,6670,6693,6711,6578,6582,6586,6590,6595,6599,6603, \\
6605,6611,6613,6622,6597,6745,6633,6676,6684,6694,6698,6717,6729, \\
6514, \mathrm{JP} 5,6638,6560,6756,6758,6570,6655,6731,6734,6755,6719,6724, \\
6705,6760,6507,6509,6558,6677,6520,6537,6563,6515,6549,6516,6530 \\
6519,6505,6527,6683,6706\end{array}$ \\
\hline & Intermediate & Super-Basmati, JP5, 6621, 6564 \\
\hline & Dwarf & 6626, IR6 \\
\hline \multirow[t]{3}{*}{${ }^{\star}$ Seed Length } & Short & $\begin{array}{l}6626, \mathrm{JP} 5,6593,6638,6621,6520,6516,6574,6623,6519,6564,6711,6758 \\
6578,6582,6588,6595,6597,6745,6676,6694,6705,6719,6724,6731,6734 \\
6760\end{array}$ \\
\hline & Medium & $\begin{array}{l}\text { IR6, } 6514,6560,6756,6758,6570,6655,6731,6755,6627,6722,6620,6654, \\
6658,6751,6664,6663,6779,6740,6766,6771,6574,6670,6693,6711,6586, \\
6590,6599,6603,6605,6611,6613,6622,6633,6684,6698,6717,6729, \\
6705,6507,6564,6509,6558,6677,6520,6537,6563,6515,6549,6516,6530, \\
6519,6527,6683,6706\end{array}$ \\
\hline & Long & Super-basmati, 6642, 6756, 6505 \\
\hline \multirow[t]{4}{*}{ Geographical distribution } & Zone-I & $6564,6638,6623,6519,6520,6574$ \\
\hline & Zone-II & $\begin{array}{l}6514,6515,6516,6595,6597,6599,6655,6740,6505,6549,6563,6605,6611, \\
6507,6683,6684,6570,6588,6711,6527,6530,6620,6558,6693,6694,6603, \\
6613,6621,6663,6664,6670,6509,6705,6706,6537,6717,6719,6642,6590, \\
6593,6724,6729,6622,6626,6627,6633,6578,6582,6654,6698,6658,6577, \\
6758,6751,6755,6560,6731,6676,6734,6756,6745\end{array}$ \\
\hline & Zone-III & 6766,6771 \\
\hline & Zone-IV & 6779,6760 \\
\hline
\end{tabular}

${ }^{*}$ Days to maturity $(\leq 100$ days $=$ Very early, $101-115$ days $=$ Early, $116-130$ days $=$ Medium, $131-145$ days $=$ Late,$\geq 145$ days $=$ Very late).

*Plant height $(\leq 110 \mathrm{~cm}=$ Semi dwarf, $111-130 \mathrm{~cm}=$ Intermediate, $\geq 130 \mathrm{~cm}=$ Tall $)$.

*Seed length ( $8 \mathrm{~mm}=$ Short grain, 8-10 mm = Medium grain, $10 \mathrm{~mm}=$ Long grain).

suggesting a close association. Similarity coefficients of 'IR6' with landraces of this group ranged from 0.25 to 0.86 .

The number of alleles detected by microsatellite markers varied from 2 to 13 with an average of 4.5 alleles per locus and were similar to those reported in basmati and nonbasmati rice varieties (Siwach et al. 2004; Neeraja et al. 2005; Ghneim Herrera et al. 2008). The 2.0-5.5 alleles per SSR locus for various classes of microsatellites were similar to those reported by Cho et al. (2000) using a 
Table 3. Details of SSR markers used, indicating their location on rice chromosomes, number of alleles detected, allele size range and polymorphism information content (PIC).

\begin{tabular}{|c|c|c|c|c|c|c|c|}
\hline Marker & Chromosome & SSR motifs & Total & Polymorphic & Size range & Difference & PIC \\
\hline RM1 & 1 & $(\mathrm{GA}) 26$ & 5 & 5 & $75-135$ & 60 & 0.678 \\
\hline RM10 & 2 & $(\mathrm{GA}) 15$ & 2 & 2 & $142-159$ & 17 & 0.124 \\
\hline RM13 & 5 & $(\mathrm{GA}) 16$ & 2 & 2 & $130-150$ & 20 & 0.336 \\
\hline RM16 & 3 & $(\mathrm{GA}) 15$ & 3 & 3 & $165-187$ & 22 & 0.256 \\
\hline RM17 & 12 & $(\mathrm{GA}) 21$ & 3 & 3 & $160-185$ & 15 & 0.395 \\
\hline RM19 & 4 & (ATC)10 & 2 & 2 & $192-252$ & 60 & 0.191 \\
\hline RM44 & 8 & $(\mathrm{GA}) 16$ & 4 & 4 & $100-125$ & 25 & 0.373 \\
\hline RM55 & 5 & (GA)17 & 2 & 2 & $216-247$ & 31 & 0.468 \\
\hline RM60 & 3 & (AATT)5AATCT(AATT) & 2 & 2 & $162-176$ & 14 & 0.394 \\
\hline RM70 & 7 & (ATT)33 & 13 & 13 & $128-167$ & 39 & 0.800 \\
\hline RM72 & 8 & (TAT)5C(ATT)15 & 6 & 6 & $151-200$ & 49 & 0.726 \\
\hline RM110 & 2 & $(\mathrm{GA}) 15$ & 5 & 5 & $138-159$ & 21 & 0.731 \\
\hline RM122 & 5 & $(\mathrm{GA}) 11$ & 5 & 5 & $229-240$ & 11 & 0.757 \\
\hline RM163 & 5 & $(\mathrm{GGAGA}) 4(\mathrm{GA}) 11 \mathrm{C}(\mathrm{GA}) 20$ & 9 & 9 & $130-175$ & 45 & 0.836 \\
\hline RM170 & 6 & (ССТ)7 & 4 & 4 & $99-119$ & 20 & 0.654 \\
\hline RM182 & 7 & (AT)16 & 8 & 8 & $328-349$ & 21 & 0.833 \\
\hline RM201 & 9 & $(\mathrm{CT}) 17$ & 4 & 4 & $144-159$ & 15 & 0.540 \\
\hline RM202 & 11 & $(\mathrm{GA}) 30$ & 5 & 5 & $161-190$ & 29 & 0.735 \\
\hline RM222 & 10 & (CT) 18 & 3 & 3 & $199-225$ & 26 & 0.545 \\
\hline RM223 & 8 & $(\mathrm{GA}) 25$ & 4 & 4 & $140-170$ & 30 & 0.623 \\
\hline RM224 & 11 & $(G A) 13$ & 4 & 4 & $118-157$ & 39 & 0.662 \\
\hline RM234 & 7 & $(\mathrm{GA}) 25$ & 3 & 3 & $133-163$ & 30 & 0.633 \\
\hline RM241 & 4 & $(\mathrm{CT}) 31$ & 5 & 5 & $104-149$ & 45 & 0.831 \\
\hline RM242 & 9 & (CT)26 & 3 & 3 & $197-255$ & 58 & 0.444 \\
\hline RM252 & 4 & $(\mathrm{GA}) 19$ & 9 & 9 & $194-262$ & 68 & 0.738 \\
\hline RM253 & 6 & $(\mathrm{GA}) 25$ & 4 & 3 & $117-146$ & 29 & 0.434 \\
\hline RM257 & 9 & (CT)24 & 3 & 3 & $132-147$ & 15 & 0.653 \\
\hline RM263 & 2 & (CT)34 & 5 & 5 & $162-199$ & 37 & 0.374 \\
\hline RM302 & 1 & (GT)30(AT)8 & 6 & 6 & $120-191$ & 71 & 0.623 \\
\hline RM310 & 8 & (GT)19 & 5 & 5 & $87-123$ & 36 & 0.766 \\
\hline RM333 & 10 & (TAT)19(CTT)19 & 4 & 4 & $166-196$ & 30 & 0.629 \\
\hline RM348 & 4 & $(\mathrm{CAG}) 7$ & 3 & 3 & $131-143$ & 12 & 0.422 \\
\hline Total & & & 145 & 142 & & & \\
\hline Average & & & 4.53 & 4.44 & & & 0.569 \\
\hline
\end{tabular}

different set of rice germplasm. However, the average numbers of alleles detected here were significantly higher than those reported in Indian aromatic rice varieties by some researchers (Nagaraju et al. 2002; Singh et al. 2004; Joshi and Behera 2006). This could be due to inclusion of several landraces of diverse origin, in this study. In 
contrast, the average numbers of alleles noticed in present study were lower than those reported previously (Ni et al. 2002; Jain et al. 2004; Xu et al. 2004; Lu et al. 2005; Brondani et al. 2006; Jayamani et al. 2007; Thomson et al. 2007). Those reports had an average of $6.8,7.8,11.9,6.6$, 14.6, 7.7 and 13.0 alleles per locus. They used rice subspecies, Indian quality rice germplasm; US rice genetic resources, traditional varieties of Brazilian rice, a diverse collection of Portuguese rice and an Indonesian rice germplasm, respectively. The inconsistency among reports might be due to the genotypes used and selection of microsatellite primers with scorable alleles.

The polymorphism information content (PIC) values, were quite high and varied (range 0.124 to 0.836 , average value $0.569)$ considerably among SSR loci. The PIC values observed in this study were comparable to those reported in some studies (Jain et al. 2004; Saini et al. 2004; Siwach et al. 2004; Lu et al. 2005; Jayamani et al. 2007; Thomson et al. 2007), but higher than those reported by Singh et al. (2004) and Joshi and Behera (2006). However, this study report lower PIC values compared to those described by $\mathrm{Xu}$ et al. (2004) and Brondani et al. (2006), who observed an average PIC value of 0.73 and 0.74 for the world collection and traditional varieties of Brazilian rice, respectively. But this difference might be linked with selection of different markers and more diverse set of varieties.

Lower bootstrap values were observed at some node points in dendrogram in present investigation as compared to Ghneim Herrera et al. (2008). The reason may be the sample size in present investigation we used 75 genotypes and in previous one only eleven genotypes were studied. The cluster analysis based on similarity coefficients places 75 rice genotypes into two major groups at 0.34 , while at 0.40 four clusters are formed. Most of the basmati-type landraces fell into the same group along with Super-basmati check variety. Cluster analysis also grouped most of the basmati landraces from different districts of Punjab together indicating that they are genetically similar with each other and have common ancestors. These rice landraces might share basmati parents in their pedigree. A similar study, conducted by Kobayashi et al. (2006) using 18 microsatellite markers, grouped 23 rice landraces into two groups, one small cluster of two indica cultivars, while other of japonica type landraces.

The microsatellite markers used in this study were well distributed amongst the 12 chromosomes, and were located in both coding and non-coding segments of the genome (Cho et al. 2000; Temnykh et al. 2000). Only three markers were monomorphic, while remaining 32 gave polymorphic alleles. RM241 located at chromosome number 4 (106.2$106.2 \mathrm{~cm}$ ) gave five polymorphic alleles with PIC value of 0.831 in Pakistani landraces while this marker was monomorphic when used previously by Kobayashi et al. 2006 in analyzing genetic diversity of an old Japanese landrace, 'Echizen'. This is a co-localized marker linked to some quantitative traits as well as qualitative traits e.g.
1,000 grain weight, awn length, biomass yield, chlorophyll contents and hull color, and flour color (www.gramene.org/db/qtl). This showed that Pakistani landrace germplasm is heterogeneous at the genomic level. Some landraces with similar morphologies in field studies proved to be diverse by DNA marker analyses.

Amplification of microsatellite markers RM70 and RM72 resulted in 13 and 6 polymorphic alleles with size ranges from $128 \mathrm{bp}$ to $167 \mathrm{bp}$ and $151 \mathrm{bp}$ to $200 \mathrm{bp}$ respectively. Separate cluster analysis of these two markers showed groups of late, early and very early maturing accessions (not included in this work). Therefore, earliness, an agronomically important trait, may be linked to these markers. There is no clear evidence for this from the literature except that microsatellite loci RM72 is present as a neighboring marker at chromosome $8(69-69 \mathrm{~cm})$ with colocalized markers (RM483, RM404, RZ617 and RM44) that were linked to days to flowering in rice (www.gramene.org/db/qtl). Another evidence is that the QTL (Quantitative Trait Locus) for days to flowering/heading (Hd-4 and Hd-5) are located on chromosome 7 and 8 respectively (Yano et al. 1997). Further analysis will be required to prove this hypothesis.

The genetic diversity of rice landraces has been studied using several methods involving their morphological and physiological characters (Oka, 1988), isozymes (Glaszmann, 1987), RFLP markers (McCouch and Tanksley, 1991) or microsatellite markers (Yang et al. 1994; Akagi et al. 1997). However, such studies generally used each rice landrace or cultivar as one single sample and did not focus on the diversity within them. On the other hand, rice landraces are reported to be heterogeneous and to include different genotypes within the population (Fukuoka et al. 2006). Microsatellite markers proved to be a useful tool for clarifying the genetic diversity among landrace genotypes. Ecogeographical adaptation of landraces was also reflected in DNA profiles also at specific loci. Three cold tolerant landraces from Malakand, Swat and Dir (Cluster-1) were grouped together showing similarity at genomic level and difference from other landraces.The reason for this grouping might be the same genetic background with limited out-crossing and farmer choice/priority in these hilly areas.

Here microsatellite analysis was an efficient tool for diversity analysis, and differentiation of rice landraces on the basis of different traits. Overall results show that Pakistani landrace germplasm of rice is not japonica type. The few landraces which grouped with JP5 in the SSRbased analysis of aromatic and quality rice implied a long, independent and complex pattern of evolution for basmati germplasm. The present investigation further indicated that genetically basmati type rice was different from that of coarse/non-aromatic and japonica type. In addition, marker-based identification and differentiation of basmati rice may help to maintain the integrity of this high quality product to the benefit of both farmers and consumers. The 
microsatellite assay generated cultivar-specific alleles in some of the genotypes screened; these may be used as DNA fingerprints for cultivar identification. This would be of enormous assistance for the establishment and defense of proprietary rights and the determination of cultivar purity.

\section{ACKNOWLEDGMENTS}

This is the part of Ph.D. thesis work of the first author. Authors are very grateful to Dr. David Lightfoot, Plant Genomics and Biotechnology Department, University of South Illinois, USA, for providing assistance in technical writing of this work and Dr. Shahid Masood Deputy Director General at PGRI, NARC, Islamabad for providing laboratory facilitation over there.

\section{REFERENCES}

AGGARWAL, R.K.; SHENOY, V.V.; RAMADEVI, J.; RAJKUMAR, R. and SINGH, L. Molecular characterization of some Indian Basmati and other elite rice genotypes using fluorescent-AFLP. Theoretical and Applied Genetics, October 2002, vol. 105, no. 5, p. 680690.

AKAGI, H.; YOKOZEKI, Y.; INAGAKI, A. and FUJIMURA, T. Highly polymorphic microsatellites of rice consist of AT repeats, and a classification of closely related cultivars with these microsatellite loci. Theoretical and Applied Genetics, January 1997, vol. 94, no. 1, p. 61-67.

ANDERSON, J.A.; CHURCHILL, G.A.; AUTRIQUE, J.E.; TANKSLEY, S.D. and SORRELLS, M.E. Optimizing parental selection for genetic linkage maps. Genome, February 1993, vol. 36, no. 1, p. 181-186.

BRONDANI, Claudio; BORBA, Tereza Cristina Oliveira; RANGEL, Paulo Hideo Nakano and BRONDANI, Rosana Pereira Vianellio. Determination of genetic variability of traditional varieties of Brazilian rice using microsatellite markers. Genetics and Molecular Biology, 2006, vol. 29, no. 4, p. 676-684.

CHO, Yong Gu; ISHII, Takashige; TEMNYKH, Svetlana; CHEN, Xiuli; LIPOVICH, Leonard; McCOUCH, Susan R.; PARK, William D.; AYRES, Nicola and CARTINHOUR, Sam. Diversity of microsatellites derived from genomic libraries and GenBank sequences in rice (Oryza sativa L.). Theoretical and Applied Genetics, March 2000, vol. 100, no. 5, p. 713-722.

COBURN, Jason R.; TEMNYKH, Svetlana V.; PAUL, E.M. and McCOUCH, Susan R. Design and application of microsatellite marker panels for semiautomated genotyping of rice (Oryza sativa L.). Crop Science, November 2002, vol. 42, no. 6, p. 2092-2099.

FELSENSTEIN, J. Confidence limits on phylogenies: an approach using the bootstrap, Evolution, 1985, vol. 39, p. 783-791.
FRANKEL, O.H and SOULÉ, M.E. Conservation and Evolution, Cambridge University Press, New York. 1981, 309 p. ISBN 0521232759.

FUKUOKA, Shuichi; SUU, Tran Danh; EBANA, Kaworu; TRINH, Luu Ngoc; NAGAMINE, Tsukasa and OKUNO, Kazutoshi. Diversity in phenotypic profiles in landraces populations of Vietnamese rice: a case study of agronomic characters for conserving crop genetic diversity on farm. Genetic Resources and Crop Evolution, June 2006, vol. 53, no. 4 , p. 753-761.

GARRIS, Amanda J.; THOMAS, H. Tai; COBURN, Jason; KRESOVICH, Steve and McCOUCH, Susan. Genetic structure and diversity in Oryza sativa L. Genetics, March 2005, vol. 169 , no. 3, p. 1631-1638.

HAMMER, Oyvind; DAVID, A.T. Harper and PAUL, D. Ryan. PAST, Paleontological Statistical Software Package for Education and Data Analysis. Palaeontological Association. USA. 2001.

GHNEIM HERRERA, Thaura; POSSO DUQUE, Duina; PÉREZ ALMEIDA, Iris; TORREALBA NÚÑEZ, Gelis; PIETERS, Alejandro J.; MARTINEZ, César P.; TOHME, Joe M. Assessment of genetic diversity in Venezuelan rice cultivars using simple sequence repeats markers. Electronic Journal of Biotechnology, 2008, vol. 11, no. 5.

GLASZMANN, J.C. Isozymes and classification of Asian rice varieties. Theoretical and Applied Genetics, 1987, vol. 74 , no. 1 , p. 21-30.

HIGHTON, R. The relationship between the number of loci and the statistical support for the topology of UPGMA trees obtained from genetic distance data. Molecular Phylogenetics and Evolution, December 1993, vol. 2, no. 4, p. 337-343.

The International Brachypodium Initiative. IRGSP: International Rice Genome Sequencing Project. The map based sequence of the rice genome. Nature, 2005, vol. 436, no. 7282 , p. $793-800$.

JAIN, Sunita; JAIN, Rajinder K. and McCOUCH, Susan R. Genetic analysis of Indian aromatic and quality rice (Oryza sativa L.) germplasm using panels of fluorescently-labeled microsatellite markers. Theoretical and Applied Genetics, September 2004, vol. 109, no. 5, p. 965-977.

JAYAMANI, P.; NEGRÃO, S.; MARTINS, M.; MAÇÃS, B. and OLIVEIRA, M.M. Genetic relatedness of Portuguese rice accessions from diverse origins as assessed by microsatellite markers. Crop Science, March 2007, vol. 47 , no. 2 , p. $879-886$.

JOSHI, Raj Kumar and BEHERA, Lambodar. Identification and differentiation of indigenous nonBasmati aromatic rice genotypes of India using 
microsatellite markers. African Journal of Biotechnology, February 2006, vol. 6, no. 4, p. 348-354.

KANG, Hee W.; CHO, Young G.; YOON, Ung H. and EUN, Moo Y. A rapid DNA extraction method for RFLP and PCR analysis from a single dry seed. Plant Molecular Biology Reporter, March 1998, vol. 16, no. 1, p. 1-9.

KOBAYASHI, Asako; EBANA, Kaworu; FUKUOKA, Shuichi and NAGAMINE, Tsukasa. Microsatellite markers revealed the genetic diversity of an Old Japanese Rice Landrace 'Echizen'. Genetic Resources and Crop Evolution, May 2006, vol. 53, no. 3, p. 499-506.

LOPEZ, S. Joseph. TaqMan based real time PCR method for quantitative detection of basmati rice adulteration with non-basmati rice. European Food Research and Technology, 2008, vol. 227, no. 2, p. 619-622.

LU, Hong; REDUS, Mare A.; COBURN, Jason R.; RUTGER, J. Neil; McCOUCH, Susan R. and TAI, Thomas H. Population structure and breeding patterns of 145 US rice cultivars based on SSR marker analysis. Crop Science, January 2005 , vol. 45 , no. 1, p. 66-76.

McCOUCH, S.R. and TANKSLEY, S.D. Development and use of restriction fragment length polymorphism in rice breeding and genetics. In: KHUSH, G.S. and TOENNIESSEN, G.H. eds. Rice Biotechnology, Biotechnology in Agriculture no. 6. International Rice Research Institute, Manila, Philippines, 1991, p. 109-133.

McCOUCH, Susan R.; TEYTELMAN, Leonid; XU, Yunbi; LOBOS, Katarayna B.; CLARE, Karen; WALTON, Mark; FU, Binying; MAGHIRANG, Reycel; LI, Zhikang; XING, Yongzhong; ZHANG, Qifa; KONO, Izumi; YANO, Masahiro; FJELLSTROM, Robert; DeCLERCK, Genevieve; SCHNEIDER, David; CARTINHOUR, Samuel; WARE, Doreen and STEIN, Lincoln. Development of 2240 new SSR markers for rice (Oryza sativa L.). DNA Research, 2002, vol. 9, no. 6, p. 199-207.

NAGARAJU, J.; KATHIRVEL, M.; KUMAR, R. Ramesh; SIDDIQ, E.A. and HASNAIN, Seyed E. Genetic analysis of traditional and evolved Basmati and non-Basmati rice varieties by using fluorescence-based ISSR-PCR and SSR markers. Proceedings of National Academy of Sciences of the United States of America, April 30, 2002, vol. 99, no. 9, p. 5836-5841.

NEERAJA, C.N.; HARIPRASAD, A.S.; MALATHI, S. and SIDDIQ, E.A. Characterization of tall landraces of rice (Oryza sativa L.) using gene-derived simple sequence repeats. Current Science, January 2005, vol. 88, no. 1, p. 149-152.

NEI, Masatoshi and LI, Wen-Hsiung. Mathematical model for studying genetic variation in terms of restriction endonucleases. Proceedings of National Academy of
Sciences of the United States of America, October 1979, vol. 76 , no. 10, p. 5269-5273.

NI, Junjian; COLOWIT, Peter M. and MACKILL, David J. Evaluation of genetic diversity in rice sub species using microsatellite markers. Crop Science, March 2002, vol. 42, no. 2, p. 601-607.

OKA, Hikoichi I. Origin of cultivated rice. Japan Scientific Societies Press, Amsterdam, New York. 1988, 250 p. ISBN 0444989196.

RABBANI, Malik Ashiq; PERVAIZ, Zahida Hassan and MASOOD, Muhammad Shahid. Genetic diversity analysis of traditional and improved cultivars of Pakistani rice (Oryza sativa L.) using RAPD markers. Electronic Journal of Biotechnology, August 2008, vol. 11, no. 3.

RAVI, M.; GEETHANJALI, S.; SAMEEYAFARHEEN, F. and MAHESWARAN, M. Molecular marker based genetic diversity analysis in rice (Oryza sativa L.) using RAPD and SSR markers. Euphytica, 2003, vol. 133, no. 2, p. 243-252.

SAINI, Navinder; JAIN, Neelu; JAIN, Sunita and JAIN, Rajinder. Assessment of genetic diversity within and among Basmati and non-Basmati rice varieties using AFLP, ISSR and SSR markers. Euphytica, January 2004, vol. 140, no. 3, p. 133-146.

SINGH, R.K.; SHARMA, R.K.; SINGH, A.K.; SINGH, V.P.; SINGH, N.K.; TIWARI, S.P. and MOHAPATRA, T. Suitability of mapped sequence tagged microsatellite site markers for establishing distinctness, uniformity and stability in aromatic rice. Euphytica, February 2004, vol. 135, no. 2, p. 135-143.

SIWACH, Priyanka; JAIN, Sunita; SAINI, Navinder; CHOWDHURY, Vijay K. and JAIN, Rajinder K. Allelic diversity among Basmati and non-Basmati long-grain indica rice varieties using microsatellite markers. Journal of Plant Biochemistry and Biotechnology, January 2004, vol. 13 , no. 1, p. 25-32.

TEMNYKH, Svetlana; PARK, William D.; AYRES, Nicola; CARTINHOUR, Sam; HAUCK, N.; LIPOVICH, Leonard; CHO, Yong Gu; ISHII, Takashige and $\mathrm{McCOUCH}$, Susan R. Mapping and genome organization of microsatellite sequences in rice (Oryza sativa L.). Theoretical and Applied Genetics, March 2000, vol. 100, no. 5, p. 697-712.

THOMSON, Michael J.; SEPTININGSIHN, Endang M.; SUWARDJO, Fatimah; SANTOSO, Tri J.; SILITONGA, Tiur S. and McCOUCH, Susan R. Genetic diversity analysis of traditional and improved Indonesian rice (Oryza sativa L.) germplasm using microsatellite markers. Theoretical and Applied Genetics, February 2007, vol. 114, no. 3 , p. 559-568. 
XU, Yunbi; BEACHELL, Henry and McCOUCH, Susan R. A marker-based approach to broadening the genetic base of rice in the USA. Crop Science, November 2004, vol. 44, no. 6, p. 1947-1959.

YANG, G.P.; SAGHAI MAROOF, M.A.; XU, C.G.; ZANG, Q. and BIYASHEV, R.M. Comparative analysis of microsatellite DNA polymorphism in landraces and cultivars of rice. Molecular and General Genetics, 1994, vol. 245 , no. 2 , p. $187-194$.

YANO, M.; HARUSHIMA, Y.; NAGAMURA, Y.; KURATA, N.; MINOBE, $\mathrm{Y}$. and SASAKI, T. Identification of quantitative trait loci controlling heading date in rice using a high-density linkage. Theoretical and Applied Genetics, 1997, vol. 95, no. 7, p. 1025-1032.

YU, S.B.; XU, W.J.; VIJAYAKUMAR, C.H.; ALI, J.; FU, B.Y.; XU, J.L.; JIANG, Y.Z.; MARGHIRANG, R.; DOMINGO, J.; AQUINO, C.; VIRMANI, S.S. and LI, Z.K. Molecular diversity and multilocus organization of the parental lines used in the International Rice Molecular Breeding Program. Theoretical and Applied Genetics, December 2003, vol. 108, no. 1, p. 131-140. 